\title{
Stability of the embankment of fine sand reinforced with geosynthetic materials
}

\author{
Kuvandik Lesov*, Mukhamedali Kenjaliyev, Akhmadjan Mavlanov, and Sherzod Tadjibaev \\ Tashkent State Transport University, Tashkent, Uzbekistan
}

\begin{abstract}
This research paper validates the significance of an assimilated attitude when choosing the design of the subgrade of railways constructed from fine sands in difficult engineering and geological conditions in the desert and steppe territories of Uzbekistan to ensure their sustainability with modern technologies and materials. The analysis of the results obtained in the calculations of the stability coefficient of the design structure of the embankment. The characteristics of the embankment soils correspond to the design data of the object "Removal of the existing railway section Dunguluk-Burgutli-Misken from the flood zone of the Shurbulak reservoir" The results of the calculations performed by the method of G. M. Shakhunyants, as well as the software "GEO 5" and "Plaxis 2D" show that the structure of the embankment with a height of more than 6 meters does not provide the required standard coefficient of stability. Complete warps of the embankment and graphs of changes in the stability coefficient of the design structure of the embankment, and with the laying of geotextiles as reinforcement of the pattern of the subgrade of railways, are given. Beneficial solutions to increase the stability coefficient of the embankment from fine sands are proposed, and the efficiency of using geosynthetic materials as a reinforcement of the pattern of the subgrade is substantiated. Theoretical calculations and analysis of prevailing embankment structures confirm the feasibility of reinforcing the structure of the subgrade erected from fine sands on the railway lines of Uzbekistan.
\end{abstract}

\section{Introduction}

Over the past period, in Uzbekistan, as a result of the state policy in the transport sector, large-scale work has been carried out to organize an effective transport system that meets the demands of the economy and the population in transport services with all types of transport. The most important tasks for railway transport in the near future are the expansion of the road network, the further improvement of railway transport, the increase in speeds and axle loads. With the further development of transport, loads on the axis of

\footnotetext{
*Corresponding author: mkenjaliyev@mail.ru
} 
locomotives can increase up to $300 \mathrm{kN}$, and loads on the axis of wagons - up to $250 \mathrm{kN}$. Train speeds are also growing.

In recent years, the construction of new railways in the central and northwestern regions of the Republic was carried out. The complexity of construction in these areas is associated with a harsh climate, difficult geological and hydrogeological conditions. The tracks of these roads mostly run through deserts. Given the lack of soils with characteristics that contribute to the stability of the subgrade, the filling of embankments was mainly carried out and will continue to be carried out by fine and dusty sands widespread in these areas.

According to the Decree of the President of the Republic of Uzbekistan dated February 7, 2017 № UP-4947, the Action Strategy for the five priority areas of the development of the Republic of Uzbekistan in 2017-2021 [1] provides for the implementation of transport and communications infrastructure projects, the development of fundamentally new technologies, and the widespread introduction of energy-saving technologies in the production. An effective solution to these complex tasks is impossible without improving innovative directions in railway construction.

The low strength and structural stability of embankments from fine and dusty sand is associated with the physical and mechanical properties of the soil. The process of reducing the strength of the subgrade of fine sands and the violation of the stability of slopes covered with fine sands when exposed to rolling stock is not well understood. In many parts of the existing tracks, there is a large amount of deformation in the subgrade. And in connection with the task of increasing freight traffic, it is necessary to develop new designs of the subgrade or strengthen existing with modern technologies and materials that provide the required stability of the structure. When designing the soil reinforcement of the subgrade, it is necessary to assess the zones of necessary reinforcement, determine their location taking into account the stress-strain state (SSS) of the soil mass [2, 3]. However, the choice of type, assessment, and ensuring the stability of the embankment of the subgrade is relevant and requires an integrated approach $[4,5]$.

\section{Methods}

\subsection{Analysis of existing design structures of the subgrade}

As a result of which reliable operation of railway infrastructure facilities is ensured, measures can be implemented during major repairs or new construction. One of the priority issues is developing and implementing ways to strengthen the subgrade of railways [6]. The use of geosynthetic materials in the construction of subgrade erected from fine sands in difficult engineering and geological conditions may be more significant from the point of view of operability and transport and the operational reliability of the structure obtaining one-time cost savings. World experience in the use of geosynthetic materials shows their versatility (wide field of application), cost-effectiveness (reduction in construction and maintenance costs, saving construction materials, shortening the time of work), environmental friendliness (reducing the use of natural resources) [7-10].

The stability analysis of the embankment of the railway track of existing subgrade structures was carried out according to the relevant design standards [11, 12] by calculating the safety margin by the method of G.M. Shahunyants [13], as well as the «GEO 5» and «Plaxis 2D» software. Calculations in the «Plaxis 2D» software were performed by specialists of the RUSKOMPOZIT group of companies. The embankment of 3 meters high was taken into account, of which the majority of the existing and newly designed sections of the railway in the desert regions of Uzbekistan consist of. The soil characteristics are taken from the geological engineering reports of «BOSHTRANSLOYIHA JSC» on the 
object «Removal of the existing railway section Dunguluk-Burgutli-Misken from the flood zone of the Shurbulak reservoir» [14]:

- fine sand dune of medium density;

- volumetric weight of soil $\gamma_{h}=1.6 \mathrm{t} / \mathrm{M}^{3}$;

- ground grip $C_{h}=0 t / M^{2}$;

- angle of internal friction of the soil $\varphi=28^{\circ}$;

- $\quad$ soil friction coefficient $f=0.5317$.

According to the design of the above object, the embankment with a height of up to 6 meters has a slope of 1:2, the width of the main subgrade area is 7.6 meters (Fig. 1).

The calculation formula developed by prof. G. M. Shahunyants, has the form:

$$
K=\frac{\sum_{l=1}^{n}\left(N_{l} f_{l}+C_{h l} l_{l}+T_{\text {hold }}\right)}{\sum_{l=1}^{n} T_{\text {shift }}}
$$

where $N$ is the normal component of the self-weight of each compartment $\mathrm{Q}_{i}$;

$T$ is tangential component of dead weight;

$l$ is length of the slip curve within the compartment in question;

$C_{h}$ and $f$ are previous values.

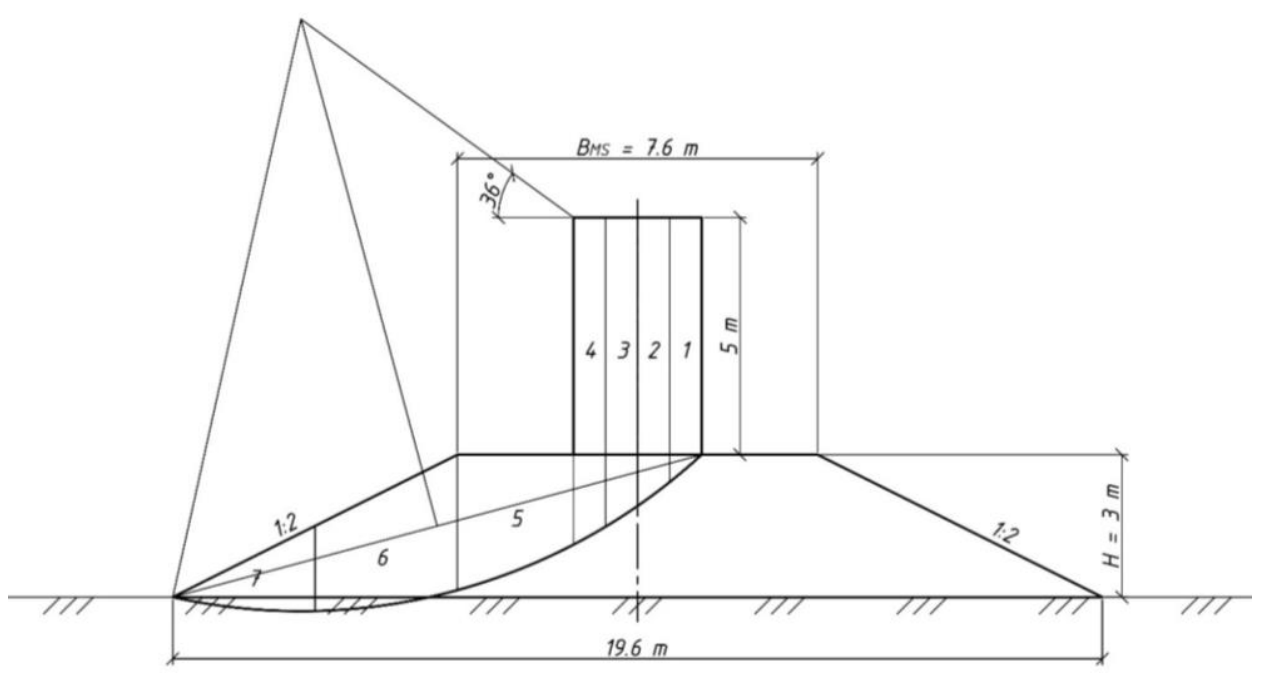

Fig. 1. Scheme for calculating the stability of the embankment with a height of $3 \mathrm{~m}$

\section{Results and Discussion}

\subsection{The results of calculating the stability coefficient of the embankment}

The calculations were performed in the spreadsheet editor Microsoft Excel and are shown in Figure 2 and 3, as well as in table 1. 
Table 1. The results of calculating the coefficient of stability of the embankment

\begin{tabular}{|c|c|c|c|}
\hline \multirow{2}{*}{$\begin{array}{c}\text { Embankment height, } \\
\mathrm{M}\end{array}$} & \multicolumn{3}{|c|}{ Embankment stability coefficient $\mathrm{K}$} \\
\cline { 2 - 4 } & $\begin{array}{c}\text { by the method of } \\
\text { G.M. Shahunyants }\end{array}$ & By «GEO 5» & $\begin{array}{c}\text { By } \\
\text { «Plaxis2D» }\end{array}$ \\
\hline 3 & 1.27 & 1.29 & 1.12 \\
\hline
\end{tabular}

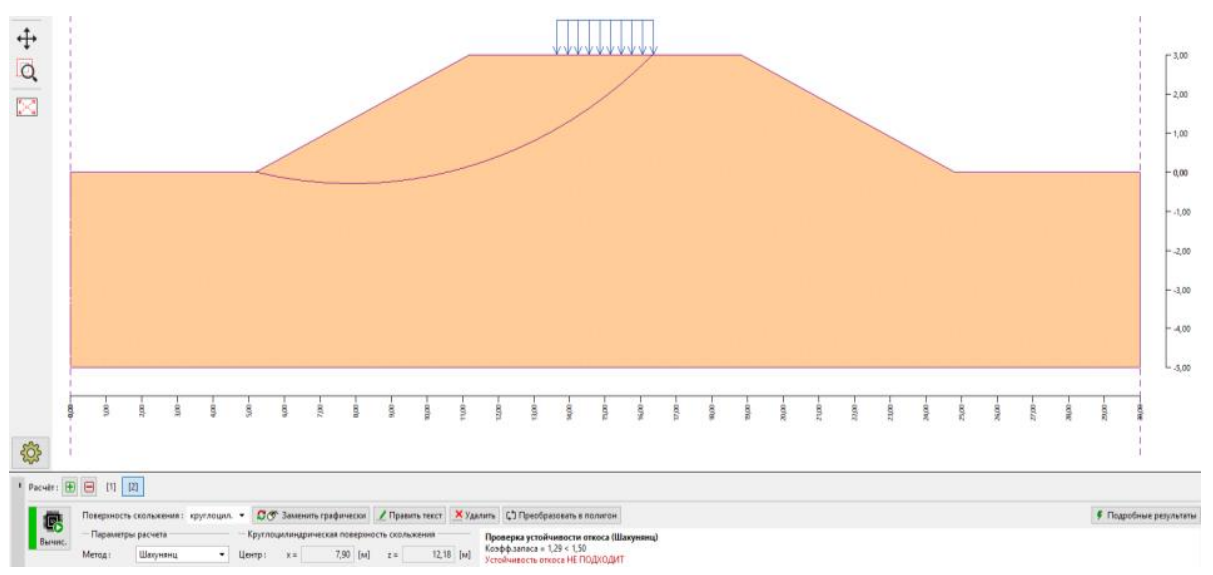

Fig. 2. The results of calculating the stability coefficient of the embankment with a height of 3 meters in software «GEO 5»

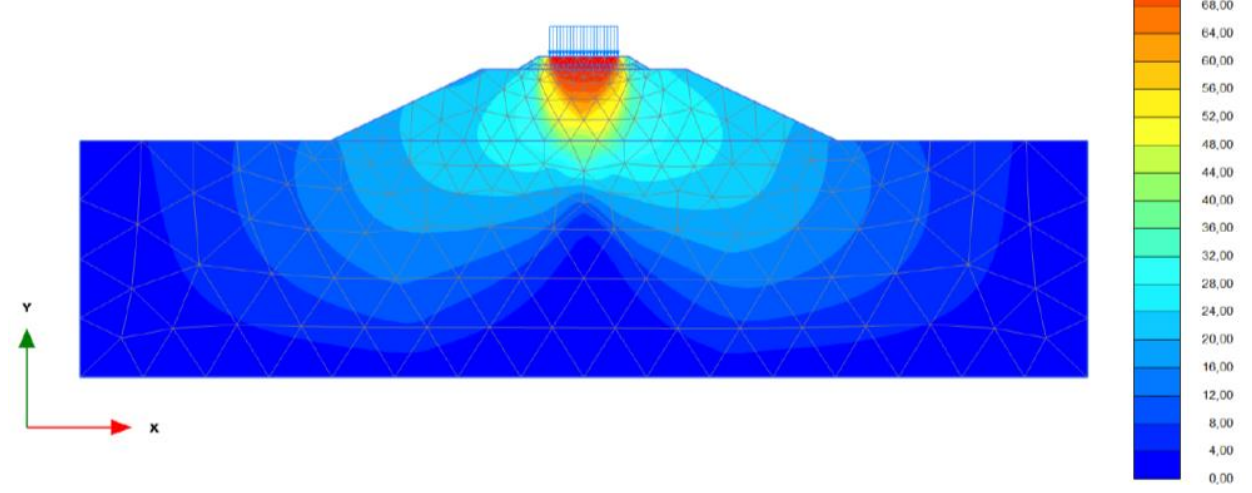




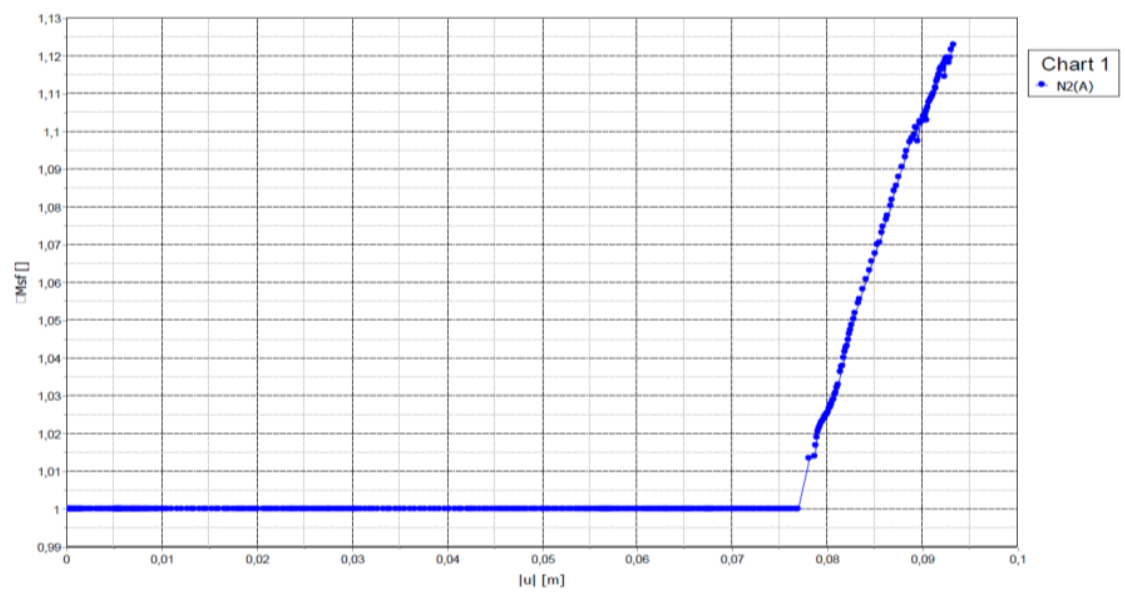

Fig. 3. Total deformations of the embankment and a graph of the stability coefficient of the embankment with a height of 3 meters in software «Plaxis 2D»

Analysis of the calculations shows that the coefficient of stability of the embankment exceeds the value $\mathrm{K}=1.2$ required by the norms, but not by much, and in the case, with the calculation in the «Plaxis2D» software, it does not reach the required value. On the whole, the structure can be considered stable, but none of the results of calculating the stability coefficient provides stability coefficient $\mathrm{K}=1.5$, which eliminates possible inaccuracies in the accepted calculations of soil characteristics. It is also worth considering that with an increase in the height of the embankment to 6 meters, the design laying of the slope does not change. In this case, the embankment stability coefficient will decrease with increasing embankment height. And when the mark of 6 meters is reached, this coefficient may be lower than the standard value $\mathrm{K}=1.2$.

Let's make calculations for the embankment 6 meters high.

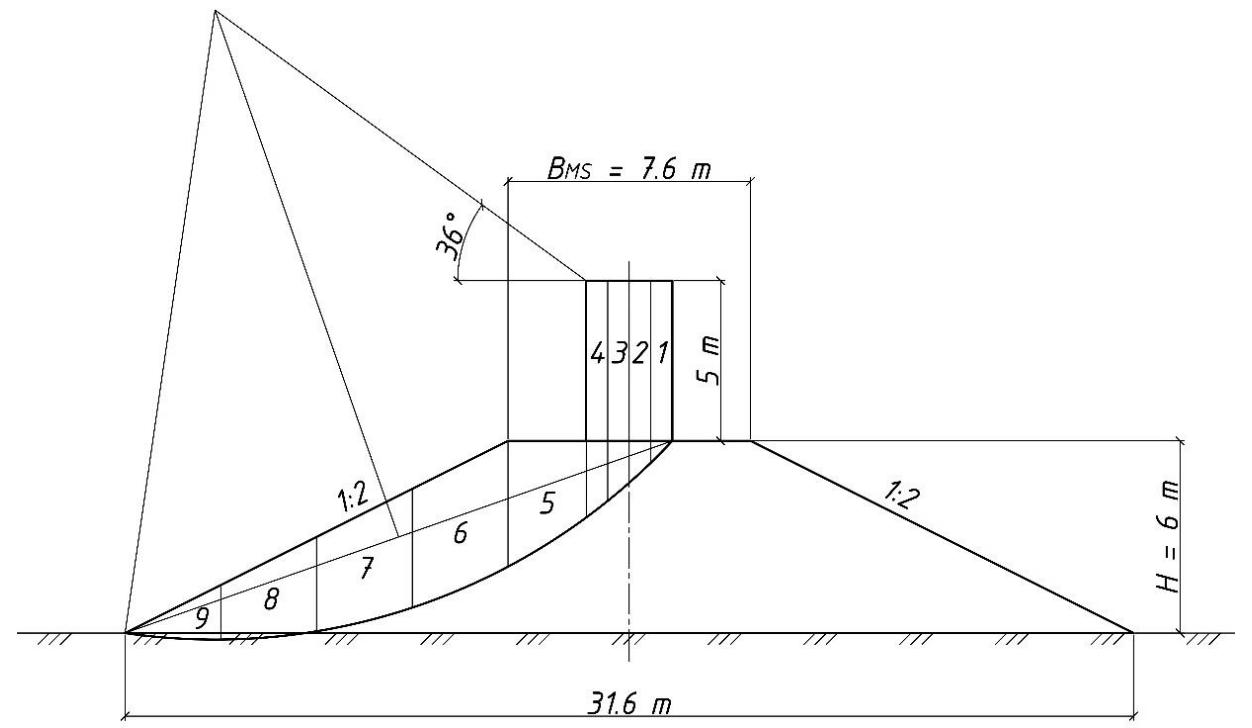

Fig. 4. Scheme for calculating the stability of the embankment with a height of $6 \mathrm{~m}$ 


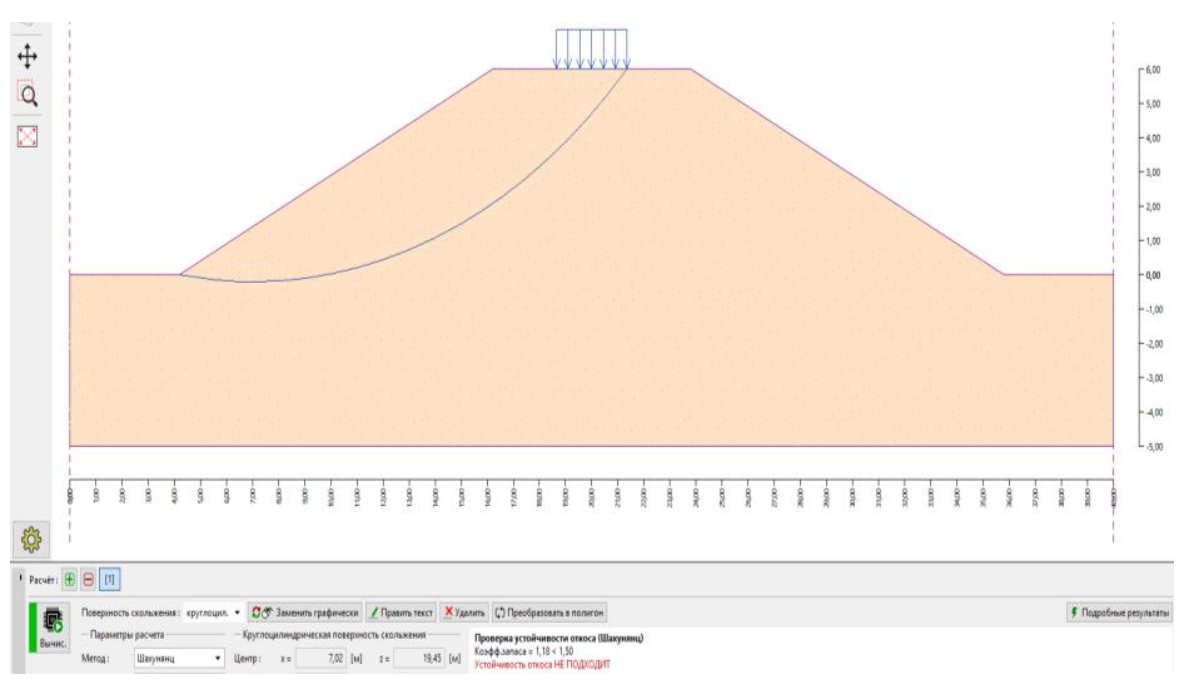

Fig. 5. The results of calculating the stability coefficient of the embankment with a height of 6 meters in software «GEO 5»

The results of calculating the stability coefficient of an embankment 6 meters high by the method of prof. G.M. Shahunyants in the spreadsheet editor Microsoft Excel and software «GEO 5» turned out to be almost identical and amounted to $K_{\text {shah. }}=1.17$ and $K_{G E O 5}=1.18$ respectively. The results show that the design of the embankment with a height of 6 meters does not provide the required standard coefficient of stability $K=1.2$.

\subsection{Design solutions to increase the stability coefficient of the embankment}

Studying foreign modern methods and technologies for solving problems of strengthening the embankment of the subgrade, one can note the widespread use of geosynthetic materials as reinforcing the body of the subgrade and slopes of embankments [15-17]. Monitoring and evaluating the quality of work to strengthen the embankment of the subgrade is carried out following the requirements of regulatory documents [18-20]. When carrying out work to strengthen the embankment of the subgrade with geosynthetic materials, the requirements given in [21] must be observed. In world practice, for similar soils and the climatic conditions of Uzbekistan, geotextiles are used with laying embankments every 1 meter of soil.

The stability calculations of the embankment were carried out according to the soil conditions of the object "Removal of the existing railway section of Dunguluk-BurgutliMisken from the flood zone of the Shurbulak reservoir". In the construction of the subgrade, geotextiles are used as reinforcement. A geotextile layer with a density of 200$400 \mathrm{~g} / \mathrm{m}^{2}$ is located at a depth of 1.2 meters from the main site of the subgrade. The calculations are performed in the software «GEO 5» and «Plaxis 2D». The calculation results are shown in Fig. 6, 7, and 8. 

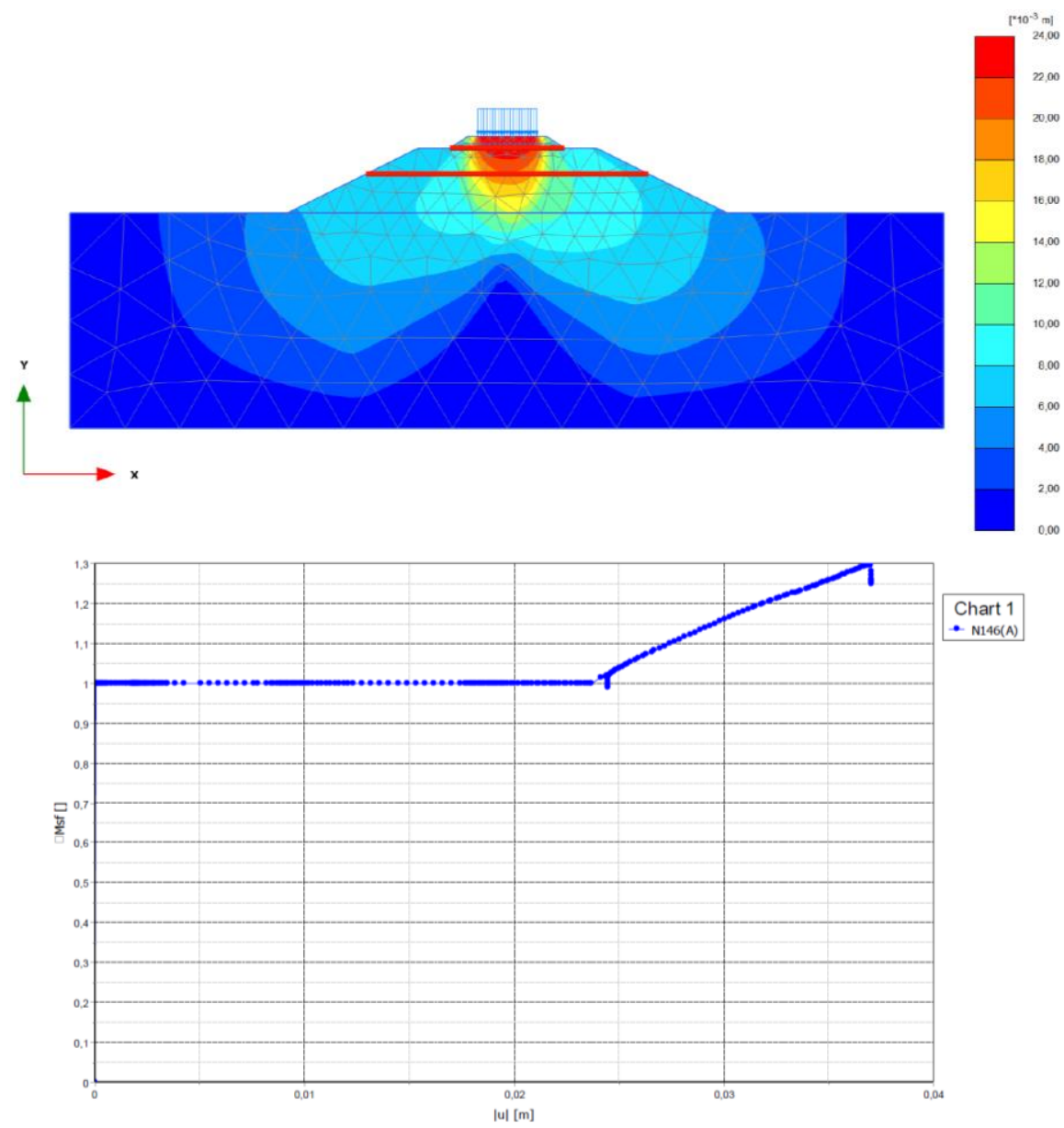

Fig. 6. Total deformations of the embankment and a graph of the stability coefficient of the embankment 3 meters high with the laying of geotextiles in software «Plaxis $2 \mathrm{D}$

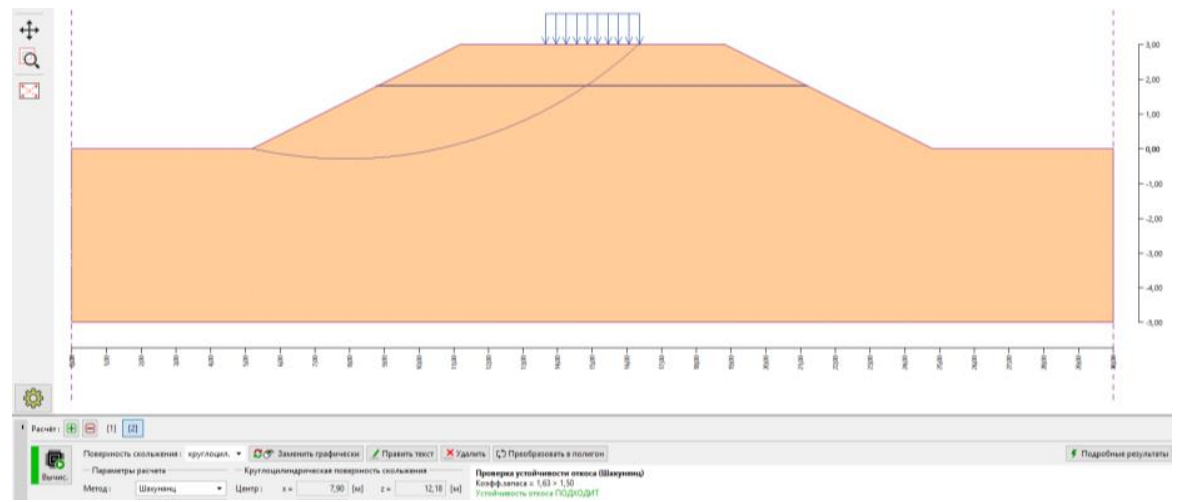

Fig. 7. The results of calculating the stability coefficient of the embankment with a height of 3 meters with the laying of geotextiles in software «GEO 5» 


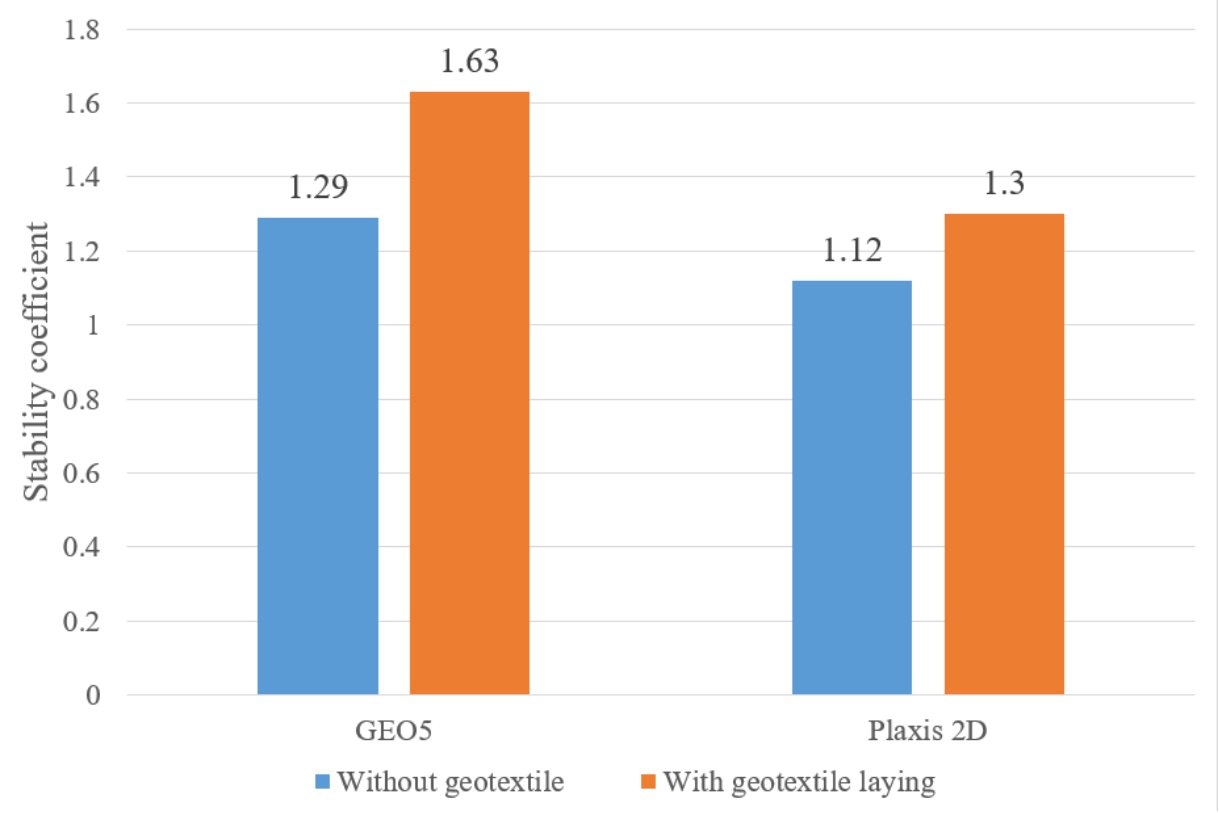

Fig. 8. A chart comparing the results of calculating the stability coefficient of an embankment 3 meters high

Analysis of the results of calculating the design of the embankment with the laying of geotextiles in the body of the subgrade allows us to conclude that it is efficient to use geosynthetic materials to strengthen the subgrade and increase the stability of the slopes of the embankment from fine sands. When reinforcing the subgrade using geotextiles, the changes in the stability coefficients of the embankment amounted to:

- with embankment height $3 \mathrm{~m}$ :

- according to calculations in software $«$ GEO $5 »-$ from $\mathrm{K}=1.29$ to $\mathrm{K}=1.63$;

- according to calculations in software «Plaxis $2 \mathrm{D} »-$ from $\mathrm{K}=1.12$ to $\mathrm{K}=1.30$;

- with embankment height $6 \mathrm{~m}$ :

according to calculations in software $«$ GEO $5 »-$ from $\mathrm{K}=1.18$ to $\mathrm{K}=1.36$.

\section{Conclusions}

Theoretical calculations and analysis of existing embankment structures used in the design and construction of railways passing through the desert and steppe regions of Uzbekistan showed that these structures do not provide the required stability. And observations on sections of existing railway lines confirm these calculations with the occurrence of precipitation on the main site of the subgrade. The considered method of reinforcing the embankment design using geomaterials has improved theoretical results. Stability factors increased to $25 \%$ and exceeded the required regulatory value. These calculations show the effectiveness of using geosynthetic materials to strengthen the structure of the embankment erected from fine sands and suggest the feasibility of strengthening the construction of the subgrade on the railway lines of Uzbekistan.

\section{References}

1. Decree of the President of the Republic of Uzbekistan dated February 7, № UP-4947 
Strategy of action in five priority areas of the development of the Republic of Uzbekistan in 2017-2021 (2017)

2. Lanis A.L. Reinforcement of the main site of a high embankment with the injection of hardening solutions Bulletin of the Siberian State University of Railway Engineering 3 (50) pp. 38-46, (2019

3. Lanis A.L. 2018 The results of modeling exploited embankments during pressure injection of hardening solutions Bulletin of the Siberian State University of Railway Engineering 3 (46) pp. 43-50, (2018)

4. Lesov KS, Tadjibaev Sh.A. and Kenjaliyev M.K., Technology for strengthening slopes of the subgrade of railroads made of sandy soils using geosynthetic materials Problems of architecture and construction 4 pp. 15-18, (2019)

5. Lesov K.S., Kenzhaliev M.K. and Tadzhibaev Sh.A., Determination of the stability of the embankment of the subgrade of railways built from fine sands International Scientific and Technical Conference "Global Partnership - As a Condition and Guarantee of Sustainable Development" 2 pp. 248-252

6. Lanis A.L., Methods of strengthening the subgrade by injection Proceedings of the Trans-Siberian Railway 3 (27) pp. 117-124, (2016)

7. Zakirov R.S. and Omarov A.D., Anti-deformation reinforcement of a subgrade made of sandy soil in Kazakhstan (Almaty: Gylym) p. 164 (1999)

8. Lesov K.S., Mirakhmedov M.M. and Tadjibaev Sh.A., 2019 World experience in the use of geosynthetic materials in subgrade designs Architecture, Construction. Design. Scientific and practical journal 2 pp. 194-197.

9. ODM 218.5.005-2010 Classification, terms, definitions of geosynthetic materials in relation to the road sector

10. ISO 10318: 2005 Geosynthetics - Terms and definitions (Geosynthetic materials. Terms and definitions)

11. SP 32.104-98. Set of rules design of the subgrade of $1520 \mathrm{~mm}$ gauge railways (Moscow, Gosstroy of the Russian Federation) p. 22, (199)

12. The code of rules of the joint venture 78.13330.2012. Roads, Updated version of SNiP 3.06.03-85.

13. Shakhunyants G.M. Railway track: textbook for high schools (Moscow, Transport) p. $479,(1987)$

14. The project of JSC "BOSHTRANSLOYIHA" Removal of the existing railway section of Dunguluk-Burgutli-Misken from the flood zone of the Shurbulak reservoir, (2019)

15. ODM 218.5.003-2010, Recommendations for the use of geosynthetics in the construction and repair of roads p. 71, (2010)

16. Guidance on the use of polymeric materials to strengthen the subgrade when repairing the track (Ministry of Railways of Russia, Moscow IKC "Akademkniga") p. 110, (2002)

17. Lesov K.S. The technology of reinforcing the embankment of the subgrade of railroads from sandy soils using geosynthetic materials Bulletin of TashIIIT 2 pp. 11$16,(2019)$

18. KMK 3.02.01-97 Earthworks, foundations and foundations

19. ShNK 3.01.01-03 Organization of construction production

20. ODM 218.2.046-2014, Recommendations on the selection and quality control of geosynthetic materials used in road construction p. 1472, (2014)

21. KMK 3.01.02-00 2000 Safety measures in construction (State Architectstroi of the Republic of Uzbekistan) p. 38 